\title{
Assessment of novel Lehmann's funnel entry trap prototypes performance to control malaria mosquito populations
}

\author{
Roger Sanou ${ }^{1,2^{*}} \mathbb{C}$, Hamidou Maïga ${ }^{1}$, Etienne M. Bilgo ${ }^{1}$, Simon P. Sawadogo ${ }^{1}$, Bazoumana B. D. Sow ${ }^{1,2}$, \\ Adama Ouema ${ }^{1,2}$, Koama Bayili ${ }^{1}$, Adrien Marie Gaston Belem², Léa Paré Toé ${ }^{1}$, Roch K. Dabiré ${ }^{1}$ \\ and Abdoulaye Diabaté ${ }^{*}$
}

\begin{abstract}
Background: There is a global consensus that new intervention tools are needed for the final steps toward malaria elimination/eradication. In a recent study in Burkina Faso, the Lehmann Funnel Entry Trap (LFET) has shown promising results in the reduction of mosquito densities, even in areas where insecticide resistance is as high as $80 \%$. The LFET requires no chemicals and is self-operated. However, one of the issues with the original LFET is the size of the funnel, which often occupies too much space within users' homes. Here, the performance of three new, smaller-sized LFET prototypes that combine a screening and killing effect on mosquitoes was assessed.

Methods: The study was carried out over three months during the rainy season in low and high malaria vector density sites, Soumousso and Vallée du Kou, respectively. The original LFET (or'Prototype 1'/'P1') was modified to produce three new prototypes, which were referred to as prototype 2 ('the Medium' or 'P2'), prototype 3 (P3) and prototype 4 (P4). Each of the new prototypes was tested on eight days per month over the three-month period to assess their effectiveness in trapping and killing mosquitoes entering houses through the windows compared to the original LFET.

Results: Overall, 78,435 mosquitoes (mainly Anopheles gambiae sensu lato) were collected in the two study sites, both in the traps and in the houses. A total of 56,430 (72\%) mosquitoes were collected from the traps. In Vallée du Kou, the original LFET caught a greater number of mosquitoes than the medium (prototype 2), whereas no difference was observed between the other new prototypes ( 3 and 4 ) and the medium. In Soumousso, both the original and medium LFETs collected significantly greater numbers of mosquitoes compared to prototypes 3 and 4.

Conclusion: This study has shown that the new LFET prototypes are effective in trapping mosquitoes in high mosquito density settings. A large-scale study with one of the prototypes will be needed to assess community acceptance of the traps and their ability to control malaria vectors.
\end{abstract}

Keywords: Prototypes, Adult mosquito trap, Anopheles gambiae, Malaria, Burkina faso

*Correspondence: sanourog@yahoo.fr; npiediab@gmail.com ${ }^{1}$ Institut de Recherche en Sciences de La Santé (IRSS)/Centre Muraz, Bobo-Dioulasso, Burkina Faso

Full list of author information is available at the end of the article

\section{Background}

Malaria has decreased dramatically over the last decade, and the number of deaths has dropped from 445,000 in 2016 to 405,000 in 2018 globally [1, 2], mainly due to the up-scaling of vector-control interventions. Current vector control relies primarily on the use of long-lasting insecticidal nets (LLINs) and indoor residual spraying

(c) The Author(s) 2021. This article is licensed under a Creative Commons Attribution 4.0 International License, which permits use, sharing, adaptation, distribution and reproduction in any medium or format, as long as you give appropriate credit to the original author(s) and the source, provide a link to the Creative Commons licence, and indicate if changes were made. The images or other third party material in this article are included in the article's Creative Commons licence, unless indicated otherwise in a credit line to the material. If material is not included in the article's Creative Commons licence and your intended use is not permitted by statutory regulation or exceeds the permitted use, you will need to obtain permission directly from the copyright holder. To view a copy of this licence, visit http://creativeco mmons.org/licenses/by/4.0/. The Creative Commons Public Domain Dedication waiver (http://creativecommons.org/publicdomain/ zero/1.0/) applies to the data made available in this article, unless otherwise stated in a credit line to the data. 
(IRS) [3]. However, the spread of insecticide resistance across Anopheles mosquito species is threatening and undermining the global effort for malaria elimination [1, 4]. In order to manage the spread of mosquito insecticide resistance, one important consideration is the effective monitoring of mosquito vector populations, a key element of vector management and assessment of mosquito borne disease [5]. Therefore, there is an urgent need to identify novel tools for malaria control.

Malaria transmission is mediated by female Anopheles mosquitoes. Female mosquitoes seek blood meals late at night in human dwellings [6-8] when people are vulnerable. Although malaria is mostly transmitted indoors, some studies in East and West Africa have shown malaria transmission occurring outdoors by mosquitoes that escape insecticides or other indoor control methods [9-12]. Mosquito entry rate and consequently disease transmission are affected by house type [13], and it is widely acknowledged that poor quality housing-constructions with wooden roofs, straw, clay bricks and roof plates, or clay roofs, for example-is generally believed to be an important contributor to ill health [14]. Recently, new approaches based on the design of house ceilings, doors, windows and eaves were developed to reduce mosquitoes entering into houses and thus transmitting disease $[15,16]$. Furthermore, approaches that exploit insect behaviour with regards to house entry have been explored as part of malaria vector control strategies [17, 18]. These ideas were brought together in the design of the original Lehmann's Funnel Entry Trap (LFET), a window trap exploiting mosquito endophilic and anthropophilic behaviours and entry route [19]. The potential of the original LFET to control mosquito densities has been demonstrated, and preliminary results showed house entry reduction by $71 \%$ in Vallée du Kou, a high mosquito density area in Burkina Faso [19]. However, the original LFET prototype occupied too much space, impacting residents' enthusiasm for continuous use. In response to this major issue, the original LFET was scaled down.

Here three smaller LFET prototypes' trapping efficiency was evaluated and compared to the original LEFT [19] in low and high mosquito density areas. In addition, this study aimed to determine a promising prototype that could be proposed/recommended as a vector control tool.

\section{Methods}

\section{Study areas}

The study was carried out in two ecological settings, Vallée du Kou and Soumousso (Fig. 1), located near Bobo-Dioulasso, Burkina Faso. Vallée du Kou $\left(11^{\circ} 23^{\prime} \mathrm{N}\right.$, $\left.4^{\circ} 24^{\prime} \mathrm{W}\right)$ is a village located to the north-west of BoboDioulasso, characterized by over 1200 ha of wooded

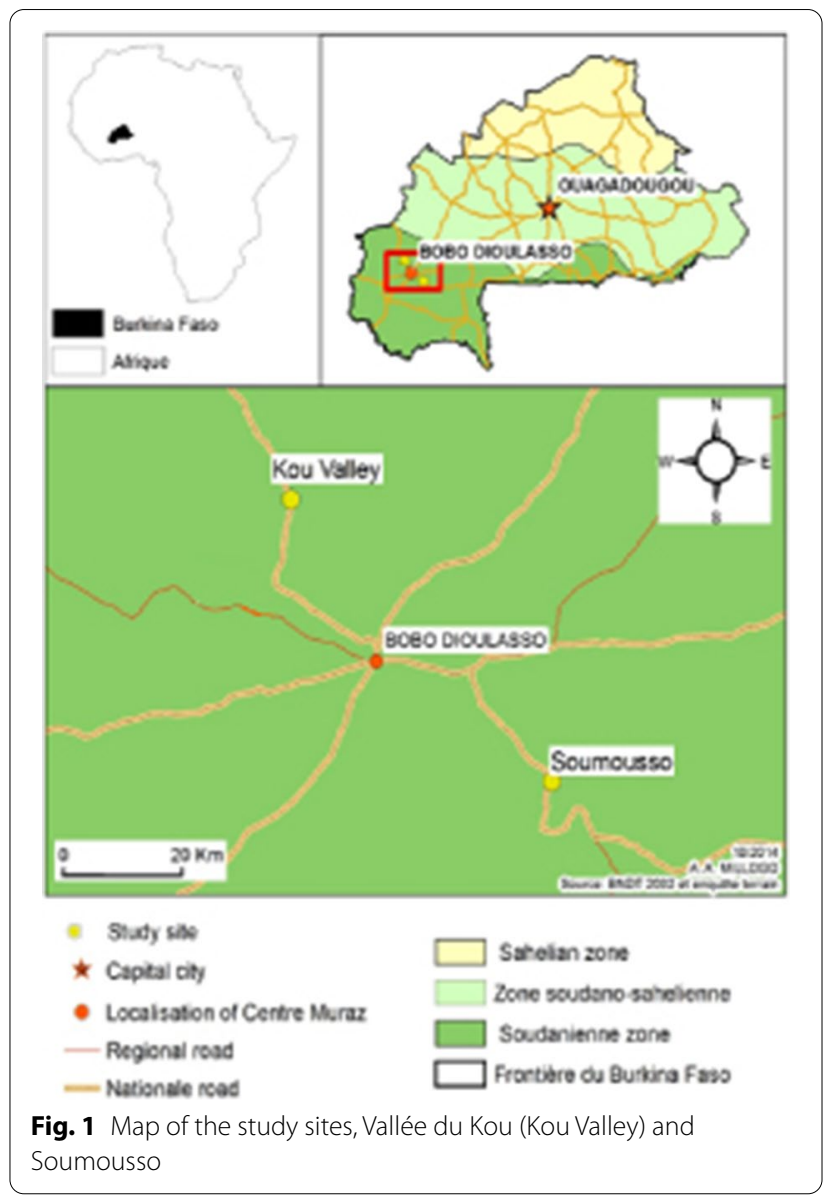

savannah. It is a rice growing area with high mosquito densities throughout the year. The trial was conducted in one village of the seven neighbourhoods separated from one another by rice fields, Vallée du Kou 3 ('VK3'). This site was chosen due to its proximity to the main tarred road. Given the presence of surface water all year round, mosquitoes are found with ease, with a peak density observed in August-September, during the rainy season. Anopheles gambiae and Anopheles coluzzii are present with a predominance of An. coluzzii throughout the year. Both species in this area are highly resistant to pyrethroids and DDT ( $k d r$ based mechanism, 0.8-0.95), and with an increase in ace-1 resistance frequency has also been reported $[20,21]$.

Soumousso $\left(11^{\circ} 04^{\prime} \mathrm{N}, 4^{\circ} 03^{\prime} \mathrm{W}\right)$, located in the south of Bobo-Dioulasso, in contrast with VK3, it is a drier setting where the dominant species are An. gambiae, and a mixture of mostly Anopheles funestus, Anopheles arabiensis, Anopheles coluzzii [22]. In this area, the mosquito density is lower compared to that of Vallée du Kou, and the dynamics of the mosquito population follow the two main seasons, with fewer mosquitoes in the dry season compared to the rainy season. 


\section{Description of the traps}

The original LFET (prototype 1, P1) was designed by Diabaté and collaborators in 2013 [19] and was made from a metal frame (length $=69 \mathrm{~cm}$, width $=51 \mathrm{~cm}$, height $=165 \mathrm{~cm}$ ) fitted with a regular mosquito net to prevent mosquitoes and other insects from escaping the trap once they enter it (Fig. 2). A funnel made from a metal frame was inserted at the top of the trap in such a way that mosquitoes approaching the window go first through the larger opening of the funnel and enter the trap through the small and rectangular opening. The first (large) opening of the funnel is $70 \mathrm{~cm}$ long and $54 \mathrm{~cm}$ diagonally, while the second (small) opening in bottom $13.3 \mathrm{~cm}$ long and large of $11.2 \mathrm{~cm}$. The small opening of the funnel is $10 \mathrm{~cm}$ away from the backside of the trap. The funnel is inserted in the frame in a way that allows the mosquitoes to enter the trap easily but prevents them from escaping. Once the mosquitoes enter the trap, they have a large space beneath the funnel where they disperse. For a mosquito to escape, it would have to fly up towards the small opening of the funnel and navigate through the $10 \mathrm{~cm}$ space separating the small opening of the funnel and the back of the frame. Ultimately, mosquitoes continue to fly to exhaustion before finding a way out. The principle of the LFET is to confine the mosquito inside the trap until dehydration and death. For the purpose of this experiment, traps were fitted with three sleeves on the side (one below, one in the middle and one on the top) through which mosquitoes were aspirated. The trap was secured to the windows using nails.
The medium (prototype 2, P2) is a smaller version of the original LFET. The funnel dimensions are similar but its height $(82.5 \mathrm{~cm})$ is half that of the original LFET $(165 \mathrm{~cm})$ (Fig. 3). Similarly, the whole trap was also covered with a net, fitted with three sleeves for mosquito collection.

The Prototype 3 (P3) was made using a metal funnel frame with the following measurements: length $=81 \mathrm{~cm}$, width $=16 \mathrm{~cm}$, height $=80 \mathrm{~cm}$ (Fig. 4). Here, the small funnel opening used as entry is a circular metal funnel, instead of rectangular as in the previous traps, with an opening size of $16.5 \mathrm{~cm}$ in diameter. Two circular openings on the right and on the left (the distance between both circular openings is $12.5 \mathrm{~cm}$ ) were made to fit the window size. Depending on the space available around the window of the house, the trap position may allow the use of only one of the openings (either right or left). When one opening is used as entry, the second would be closed and covered with netting. The volume of the trap was made of a horizontal and rectangular metal frame (length $=110 \mathrm{~cm}$, width $=16 \mathrm{~cm}$, height $=56 \mathrm{~cm}$ ). A net covered the trap on the backside of the funnel and was fitted with five sleeves allowing mosquito collection.

The prototype 4 (P4) is similar to P3 in terms of size and funnel type but has an additional circular funnel frame. This small $(9 \mathrm{~cm}$ long) circular funnel gives access to the space beneath.

The distance between the end of the circular pipe and the back of the trap is $10 \mathrm{~cm}$. In addition, P4 was equipped with a mirror for the inhabitants' personal
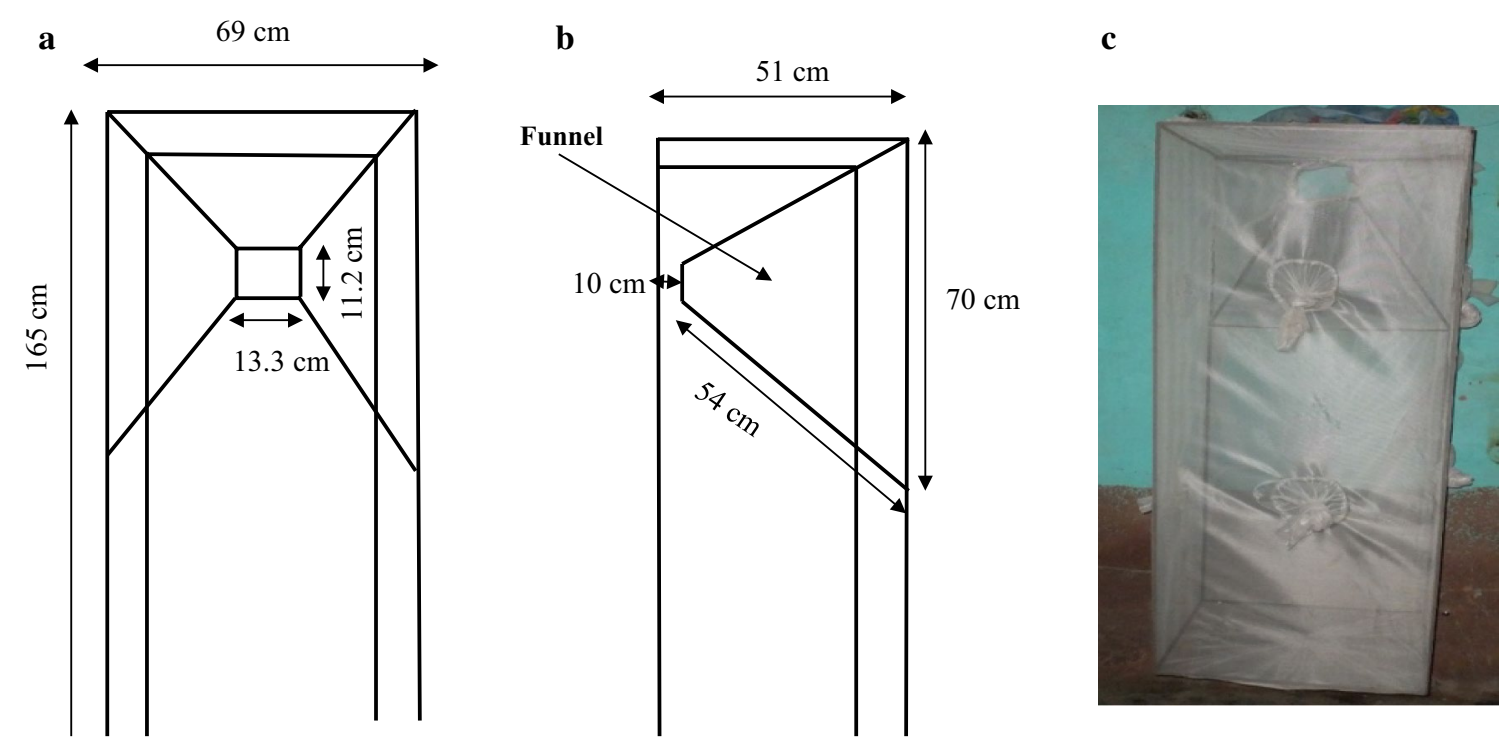

Fig. 2 Dimensions of the trap, front and side view. a Inserts front view: $69 \mathrm{~cm}$ wide $\times 165 \mathrm{~cm}$ high; $13.3 \mathrm{~cm}$ long $\times 11.2 \mathrm{~cm}$ wide (small opening of the funnel). $\mathbf{b}$ Inserts side view: $51 \mathrm{~cm}$ depth of the trap, $70 \mathrm{~cm}$ long $\times 54 \mathrm{~cm}$ diagonal (large opening of the funnel); $10 \mathrm{~cm}$ distance of the small opening of the funnel from the backside of the trap (Diabaté et al. [19]); c original prototype outside view inside a house 


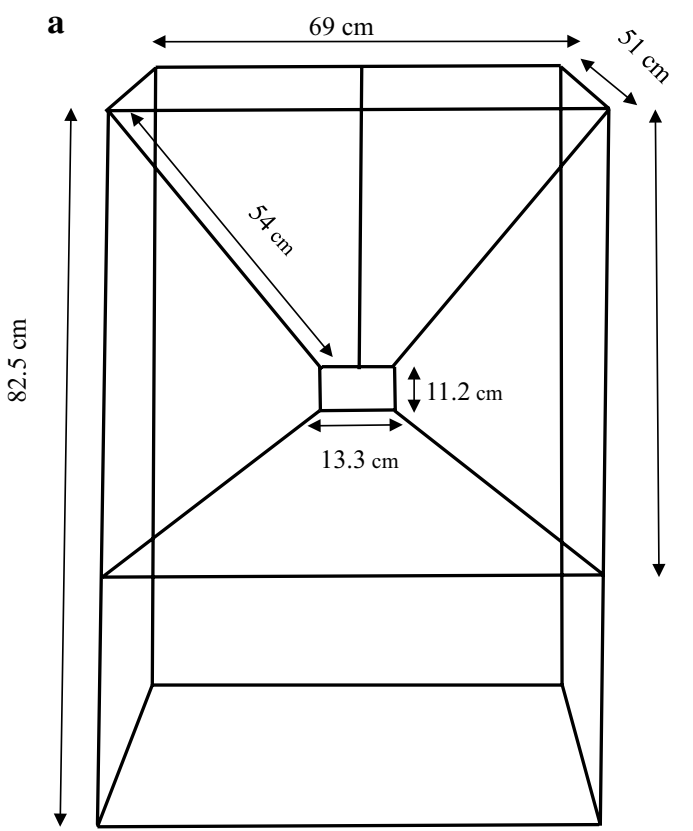

b

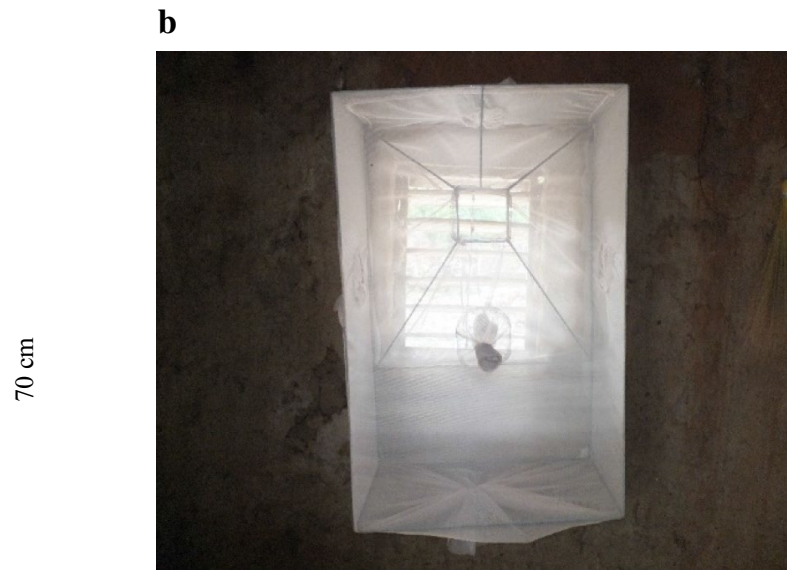

Fig. 3 a Dimensions of the trap, front and side view. Inserts front view: $69 \mathrm{~cm}$ wide $\times 82.5 \mathrm{~cm}$ high; $13.3 \mathrm{~cm}$ long $\times 11.2 \mathrm{~cm}$ wide (small opening of the funnel). Inserts side view: $51 \mathrm{~cm}$ depth of the trap, $70 \mathrm{~cm}$ long $\times 54 \mathrm{~cm}$ diagonal (large opening of the funnel); $10 \mathrm{~cm}$ distance of the small opening of the funnel from the backside of the trap. $\mathbf{b}$ Prototype 2 outside view inside a house

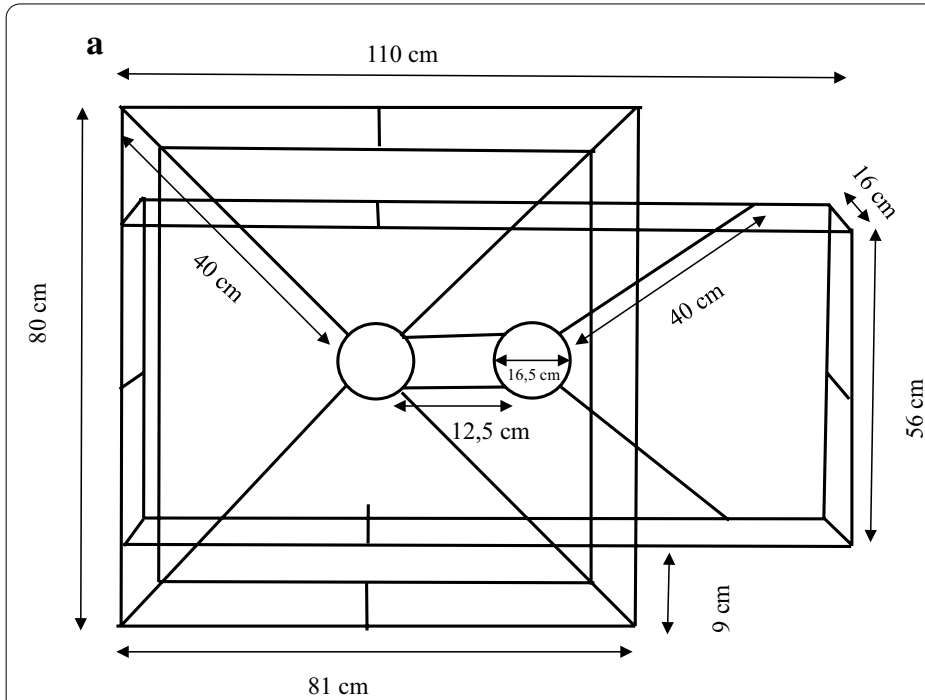

b

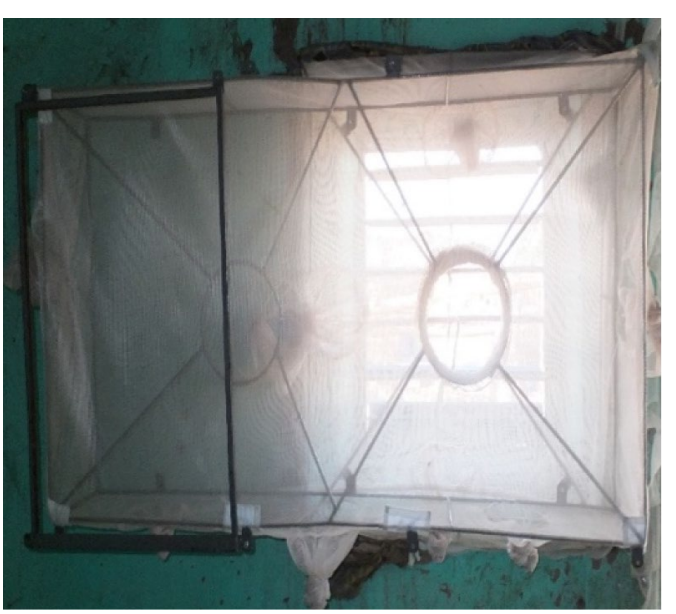

Fig. 4 a Dimensions of the trap, inserts front view. $16 \mathrm{~cm}$ wide $\times 80 \mathrm{~cm}$ high; $16.5 \mathrm{~cm}$ diameter (circular opening of the funnel), $56 \mathrm{~cm}$ depth of the trap, $81 \mathrm{~cm}$ long $\times 40 \mathrm{~cm}$ diagonal (large opening of the funnel); $10 \mathrm{~cm}$ distance of the small opening of the funnel from the backside of the trap. $\mathbf{b}$ Prototype 3 outside view inside a house, with circular funnel as entrance

use, which would make it valuable for other functions beyond controlling mosquito populations. This may help increase the acceptability and sustained use of the trap (Fig. 5). As with P3, this trap was also outfitted with five sleeves enabling mosquito collection.

\section{Study design and mosquito collection}

Three of each of the new LFET prototypes (medium/P2), P3 and P4) were tested in the two selected ecological settings along with three of the original LFET design (P1) for comparison purposes. The performance of the traps was 


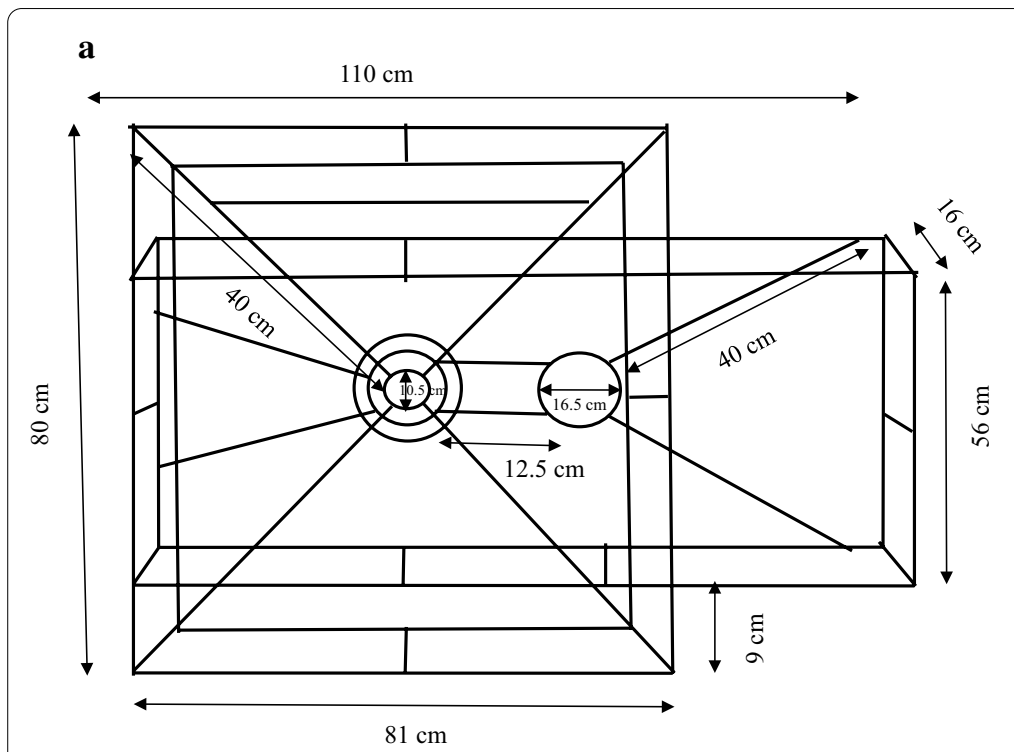

b

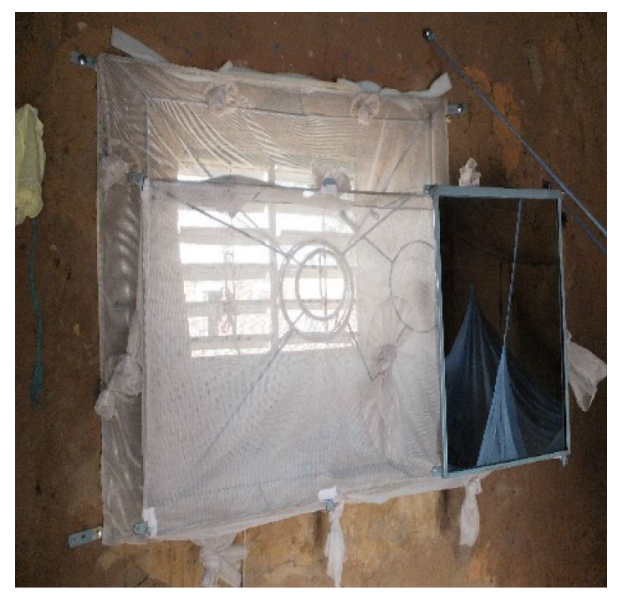

Fig. 5 a Dimensions of the trap, inserts front view. $16 \mathrm{~cm}$ wide $\times 80 \mathrm{~cm}$ high; $16.5 \mathrm{~cm}$ diameter (circular opening of the funnel), $56 \mathrm{~cm}$ depth of the trap, $81 \mathrm{~cm}$ long $\times 40 \mathrm{~cm}$ diagonal (large opening of the funnel); small circular funnel diameter $10.5 \mathrm{~cm}$, distance from the beginning of the large circular to the end of small circular $9 \mathrm{~cm}$ and $10 \mathrm{~cm}$ distance of the small opening of the funnel from the backside of the trap. $\mathbf{b}$ Prototype 4 outside view inside a house, with small circular funnel entrance

assessed in terms of the number of malaria mosquitoes trapped as well as other mosquitoes entering the house through the window. A total of 12 houses, corresponding to 12 traps, were chosen in each site (a total number of 24 traps produced for both sites). Only houses with a single room, single window (similar size with a metal frame) and single door were selected for the study. Each of the houses were at least $10 \mathrm{~m}$ apart from each other. All of the traps were installed on the same day between 15:00 and 17:00 with a two-day rotation between houses according to a Latin square plan, to reduce biases linked to house inhabitants' attraction. After installation, all the traps were simultaneously used, and checked every morning for eight consecutive days per month, for collection of all mosquitoes dead or alive in the traps for morphological identification. To ensure that mosquitoes had no other alternative except the windows to enter the house, small holes in ceilings and walls were blocked using sponges or cloth, and a curtain was placed at the entrance of each house (Fig. 6). The inhabitants were informed of the aim of the study and, therefore, free to use their doors as they wished. The window where the LFET was fitted was left open throughout to allow mosquitoes to enter the house. Traps were installed the day before prior to mosquito sampling over eight consecutive days per month, from September to November in VK3 and Soumousso.

Traps were emptied from 07:00 to 09:00, using a mouth aspirator in addition to pyrethrum spray catches [23] performed in the corresponding house. All the mosquitoes

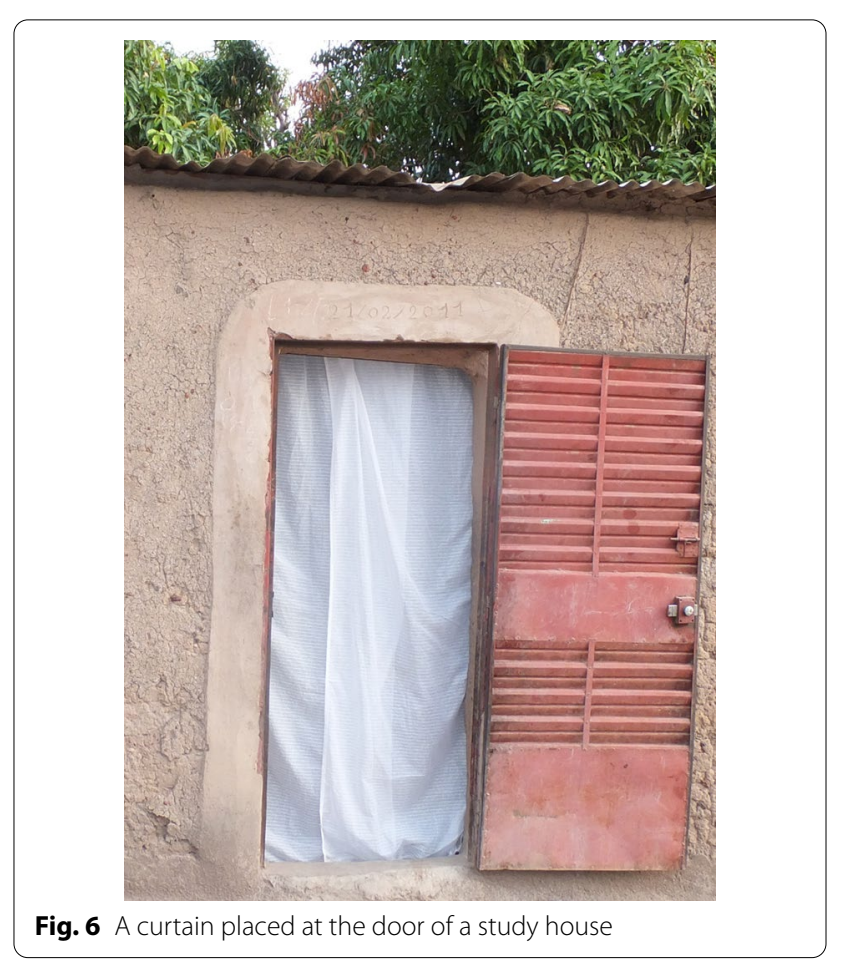

caught were kept in a single cup, then killed with chloroform and morphologically identified on site. The daily work on site consisted of mosquito collection, sorting, identification, sexing according to Gillies and De Meillon 
[24], counting and scoring per genus, species and physiological status (unfed, blood fed, gravid), and the numbers were recorded on a spreadsheet. All traps set up each month were removed at the end of the eight-day period.

\section{Statistical analysis}

Microsoft Excel 2007 (Microsoft ${ }^{\circledR}$, New York, USA) was used to record the data, and R-3.6.2 (package dplyr, questionr, and coin) was used for statistical analyses and to produce the graphs.

In the study, three main variables were analysed: (1) $\mathrm{T}=\mathrm{Tt}+\mathrm{Th}, \mathrm{T}=$ Total number of An. gambiae sensu lato (s.l.) collected in the trap and in the house, $\mathrm{Tt}=$ total number of mosquitoes collected in trap, $T h=$ total number of mosquitoes collected in the house; (2) $\mathrm{P}$ $(\%)=(\mathrm{Tt} / \mathrm{T}) * 100, \mathrm{P}=$ Proportion (\%) of mosquito entry reduction in the house and (3) $\mathrm{Dr}=\mathrm{T} / 24, \mathrm{Dr}=$ daily removal of mosquitoes per site over 24 days.

The number of mosquitoes in the traps and the matching houses did not follow a normal distribution. Therefore, a one-way non-parametric analysis of variance (Kruskal Wallis test) was used to determine whether there was difference between the traps in terms of numbers of mosquitoes collected and to assess their overall performance.

The post-hoc test was used for multiple comparisons of mean numbers of mosquitoes between traps (Bonferroni). In order to meet this post-hoc test assumption, a Tukey test for multiple comparisons was used to confirm the results.

The effects of monthly collection in mosquito density reduction were evaluated using a Levene's test for homogeneity of variance (centre $=$ median) with a Wilcoxon rank sum test and a p value bonferroni adjustment method. A Tukey multiple comparison of means with 95\% family-wise confidence level test was used for pairwise comparison between LFET prototypes.

To assess whether the traps caught more mosquitoes than those that entered in the matching houses, a comparison using Wilcoxon rank sum test with a holm p-value adjustment method was used.

\section{Results \\ Mosquito density reduction}

Overall, 78,435 mosquitoes were collected in the two study sites and were composed of 76,558 (98\%) An. gambiae s.l. (Table 1) and 1,877 (2\%) other species, which included An. funestus, Anopheles coustani, Anopheles flavicosta, Anopheles pharoensis, Anopheles rufipes, Mansonia sp, Culex sp and Aedes sp (Table 2). Out of 76,558 An. gambiae mosquitoes collected in both traps and houses, 75,471 were caught in VK3 and 1087 in Soumousso, whereby $72 \%$ and $60 \%$ respectively were collected from the traps (Table 1 ).

In VK3, the original LFET (P1) collected a daily average number of mosquitoes ranged from (36 to 675) in November (the end of the rainy season) and September (mid rainy season) respectively, while the medium LFET (P2) collected (26 to 414) and prototypes 3 and 4 collected (17 to 635) and (19 to 490), respectively (Fig. 7a).

In Soumousso, the daily average number of mosquitoes collected were $(0-9,0-19,0-2)$ and $(0-4)$ mosquitoes per trap during the trapping period for original, medium, P3 and P4, respectively (Fig. 7b). The new traps (P3 and P4) performed better in terms of house entry reduction in high mosquito density VK3, with $69 \%$ of mosquitoes denied access to the houses as compared to $36 \%$ for P3 and 39\% for P4) in the low-density site, Soumousso. In addition, during the study in VK3, the original LFET reduced house entry by $78 \%$, as compared to $70 \%$ for the medium LFET. The original LFET (P1) reduced mosquito entry by $73 \%$ while the new prototypes (medium (P2), P3, and $\mathrm{P} 4$ ) reduced house entry by a range of $36 \%$ (P3) to 73\% (medium) in Soumousso (Table 1).

The average daily $A n$. gambiae mosquito removal (Dr) was 262/house/night/trap in VK3 and 3.77/house/ night/trap in Soumousso during the study period,

Table 1 Total and proportion of male and female Anopheles gambiae s.l. mosquitoes collected per trap vs house per village

\begin{tabular}{|c|c|c|c|c|c|c|c|}
\hline \multirow[t]{2}{*}{ Village/type of trap } & \multicolumn{2}{|l|}{ VK3 } & \multirow{2}{*}{$\begin{array}{l}\text { Total } \\
\text { (trap + house) }\end{array}$} & \multicolumn{2}{|l|}{ Soumousso } & \multirow{2}{*}{$\begin{array}{l}\text { Total } \\
\text { (trap+house) }\end{array}$} & \multirow{2}{*}{$\begin{array}{l}\text { Trap (\%) } \\
\text { in both sites }\end{array}$} \\
\hline & Trap, \% (n) & House, \% (n) & & Trap, \% (n) & House, $\%(n)$ & & \\
\hline Original & $78.64(18,230)$ & $21.35(4950)$ & 23,180 & $73.27(233)$ & $26.73(85)$ & 318 & 78.6 \\
\hline Medium & $70.21(10,130)$ & $29.79(4298)$ & 14,428 & $72.80(289)$ & $27.20(108)$ & 397 & 70.3 \\
\hline Prototype 3 & $69.53(13,135)$ & $30.47(5755)$ & 18,890 & $35.90(56)$ & $64.10(100)$ & 156 & 69.3 \\
\hline Prototype 4 & $69.04(13,099)$ & $30.96(5874)$ & 18,973 & $38.89(84)$ & $61.11(132)$ & 216 & 68.7 \\
\hline Total & $72.33(54,594)$ & $27.66(20,877)$ & 75,471 & $60.90(662)$ & $39.10(425)$ & 1087 & 72.2 \\
\hline
\end{tabular}

$\mathrm{n}=$ number of mosquitoes per trap or in house, $(\%)=$ proportion of $(n)$ mosquitoes in trap or in house/total (trap + house) 
Table 2 Numbers of other mosquito species caught in trap versus house in both sites over the study period

\begin{tabular}{|c|c|c|c|c|c|c|c|c|c|c|c|c|}
\hline \multirow[t]{2}{*}{ Species } & \multicolumn{6}{|l|}{ VK3 } & \multicolumn{6}{|c|}{ Soumousso } \\
\hline & Original & Medium & P3 & P4 & $\begin{array}{l}\text { Total } \\
\text { species/ } \\
\text { trap }\end{array}$ & House & Original & Medium & P3 & P4 & $\begin{array}{l}\text { Total } \\
\text { species/ } \\
\text { trap }\end{array}$ & House \\
\hline Culex spp. & 369 & 275 & 183 & 142 & 969 & 538 & 42 & 33 & 15 & 16 & 106 & 153 \\
\hline An. pharoensis & 8 & 9 & 7 & 5 & 29 & 3 & 1 & 0 & 2 & 0 & 3 & 0 \\
\hline Mansonia spp. & 6 & 12 & 5 & 5 & 28 & 3 & 0 & 0 & 0 & 0 & 0 & 0 \\
\hline An. coustani & 5 & 8 & 7 & 3 & 23 & 3 & 0 & 1 & 0 & 0 & 1 & 0 \\
\hline An. rufipes & 0 & 0 & 0 & 0 & 0 & 0 & 1 & 0 & 0 & 1 & 2 & 2 \\
\hline An. funestus & 0 & 0 & 0 & 0 & 0 & 0 & 3 & 2 & 0 & 0 & 5 & 0 \\
\hline $\begin{array}{l}\text { An. flavicosta } \\
\text { Aedes. spp }\end{array}$ & $\begin{array}{l}0 \\
0\end{array}$ & $\begin{array}{l}0 \\
0\end{array}$ & $\begin{array}{l}0 \\
0\end{array}$ & $\begin{array}{l}0 \\
0\end{array}$ & $\begin{array}{l}0 \\
0\end{array}$ & $\begin{array}{l}0 \\
0\end{array}$ & $\begin{array}{l}1 \\
0\end{array}$ & $\begin{array}{l}6 \\
1\end{array}$ & $\begin{array}{l}0 \\
0\end{array}$ & $\begin{array}{l}0 \\
0\end{array}$ & $\begin{array}{l}7 \\
1\end{array}$ & $\begin{array}{l}0 \\
1\end{array}$ \\
\hline Total & 388 & 304 & 202 & 155 & 1,049 & 547 & 48 & 43 & 17 & 17 & 125 & 156 \\
\hline
\end{tabular}

$\mathrm{P}=\mathrm{LFET}$ prototype

(Fig. 8) summarizes the variance of the number of mosquitoes collected per trap/month/site.

The seasonal effect of month on the mosquito collection in traps showed a significant variation according to the study site (Kruskal-wallis, $\chi^{2}=10.9, \mathrm{df}=3$, $\mathrm{p}=0.012$ in VK3; and $\mathrm{x}^{2}=40.7, \mathrm{df}=3, \mathrm{p}<0.0001$ in Soumousso). The variation level in performance between the traps was confirmed, by Levene's test for homogeneity of variance (centre $=$ median) (group $284, \mathrm{df}=3, \mathrm{~F}$ value $=1.9, \operatorname{Pr}(>\mathrm{F})=0.13$ in $\mathrm{VK} 3)$ and (group 283, $\mathrm{df}=3, \mathrm{~F}$ value $=6.56 \operatorname{Pr}(>\mathrm{F})<0.001$ in Soumousso).

The original LFET caught a greater number of male and female An. gambiae mosquitoes than the medium (P2) $(p=0.014)$, whereas no difference was observed between the medium and other new prototypes (P3 and P4) in VK3 (Fig. 9a).

In Soumousso, the original (P1) and medium (P2) traps collected a similar number of male and female An. gambiae, but significantly higher than that of Prototypes 3 and $4(\mathrm{p}<0.0001)$ (Fig. 9b). A greater number of mosquitoes were caught in the traps compared to the matching houses $\left(\mathrm{p}^{<} 0.0001\right)$ (Additional file 1: Fig. 10).

\section{Gonotrophic status of collected mosquitoes}

Out of 76,558 An. gambiae caught in both traps and houses, 58,439 (76\%) were females and 18,119 (24\%) were males. Of the females, 42,116 (72\%) were caught in the traps whereas $16,323(28 \%)$ were collected in the houses. Of the 42,116 trapped mosquitoes, 18,227 were unfed and likely seeking a blood meal represented (43\%), while 19,994 (48\%) were blood fed and 3895 (9\%) were gravid females (Table 3).

\section{Discussion}

The objective of this study was to assess the modified LFET prototypes' performance in terms of suppressing malaria vectors, and to determine the most promising prototype as a vector control tool. The new LFET designs have shown the potential to reduce malaria mosquito densities in VK3. Conversely, in Soumousso, aside from the medium (P2), the new prototypes showed a relative low-density mosquito reduction in the houses compared to the original (P1). In addition to An. gambiae, other mosquito species responsible for neglected tropical diseases such as lymphatic filariasis and dengue were collected.

These results are consistent with the previous study [19] where the original design (P1) was able to reduce the number of mosquitoes from 70 to $80 \%$ in houses in a high mosquito density area. This shows that the size of the new prototypes did not impact on their performance. In addition to the smaller size (reducing the cost of manufacturing) of the modified LFET, Prototype 4 has a mirror that can be used by residents, making the trap design more attractive and acceptable to potential users. The new traps cost $\sim \$ 35, \sim \$ 40$ and $\sim \$ 41$ (USD) for the medium (P2), prototype 3 , and prototype 4 , respectively. This compares to $\$ 42$ for the original LFET (Table 4).

The new prototypes were able to block the entry of malaria mosquitoes and other insects into the house, and thus prevent the harmful effects of mosquito bites. The design of the medium LFET was quite similar to the original aside from the height of the enclosure. However, the funnel was the same, which could explain why this design performed better than the other new prototypes in low mosquito density and similarly in high density. The circular funnel of prototypes 3 and 4 may explain why they did not catch as many mosquitoes. Moreover, 

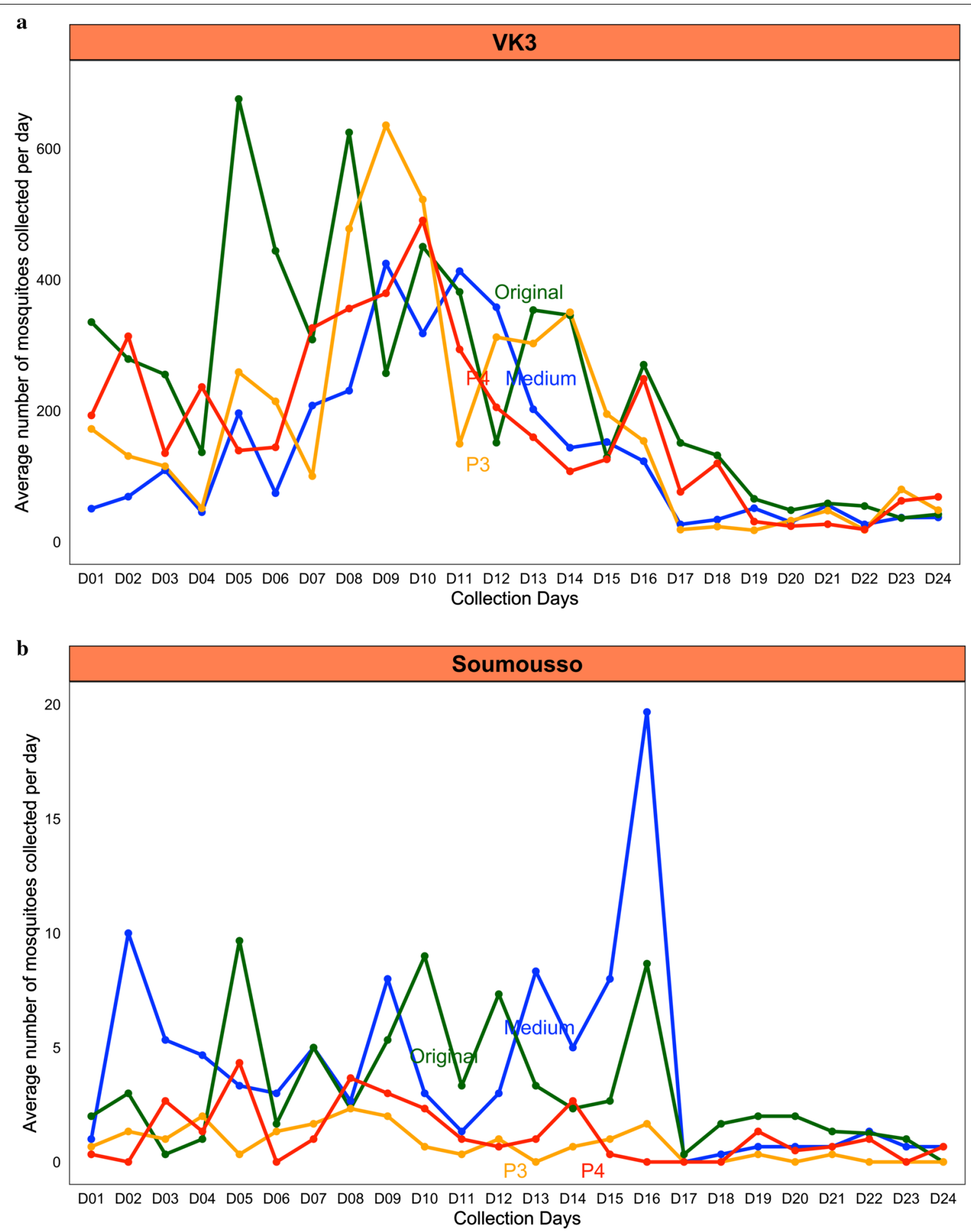

Fig. 7 Mean number of mosquitoes collected per Lehmann's Funnel Entry Trap prototype/day. a In VK3 and b in Soumousso

the smaller, horizontal enclosure screen and reduced airflow in prototypes 3 and 4 may contribute to the lower number of mosquitoes compared to the original (P1) and medium (P2). Several studies have demonstrated that some variables such as vertical or horizontal screens, air flow and direction, trap colour, screen mesh size, etc. could affect the trap's effectiveness $[25,26]$. The minimal expected trapping rate that is required for such a trap to 


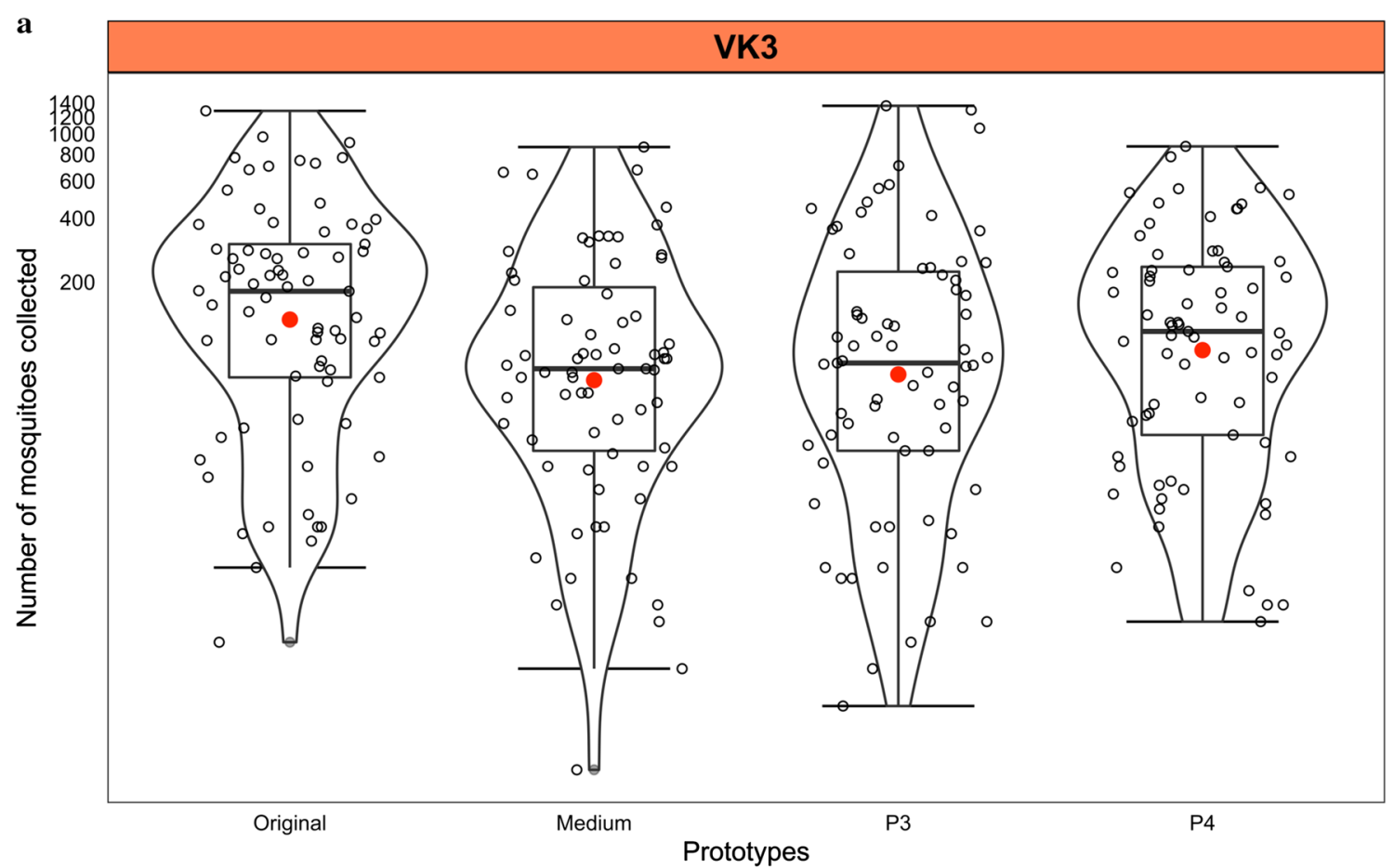

b

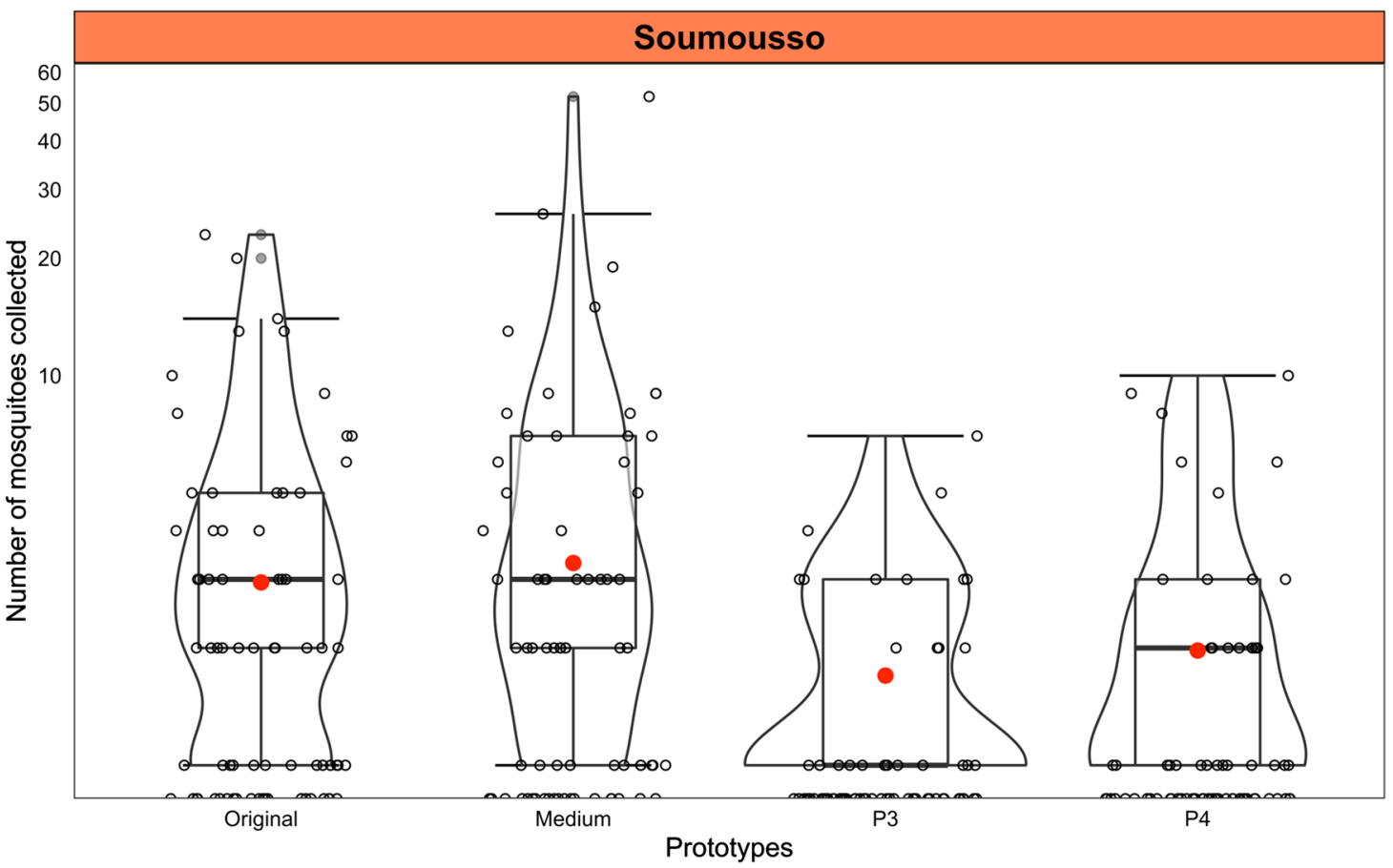

Fig. 8 Number of mosquitoes collected per trap prototype $\mathbf{a}$ in VK3 and $\mathbf{b}$ in Soumousso

be effective to protect the inhabitants is a $70 \%$ density reduction from what is expected with other malaria control means [27].
Since the establishment of a link between mosquitoes and malaria transmission [11], house screening was one of the first experiments used as part of malaria vector management [28]. Recent studies using house screening 
a

$95 \%$ family-wise confidence level

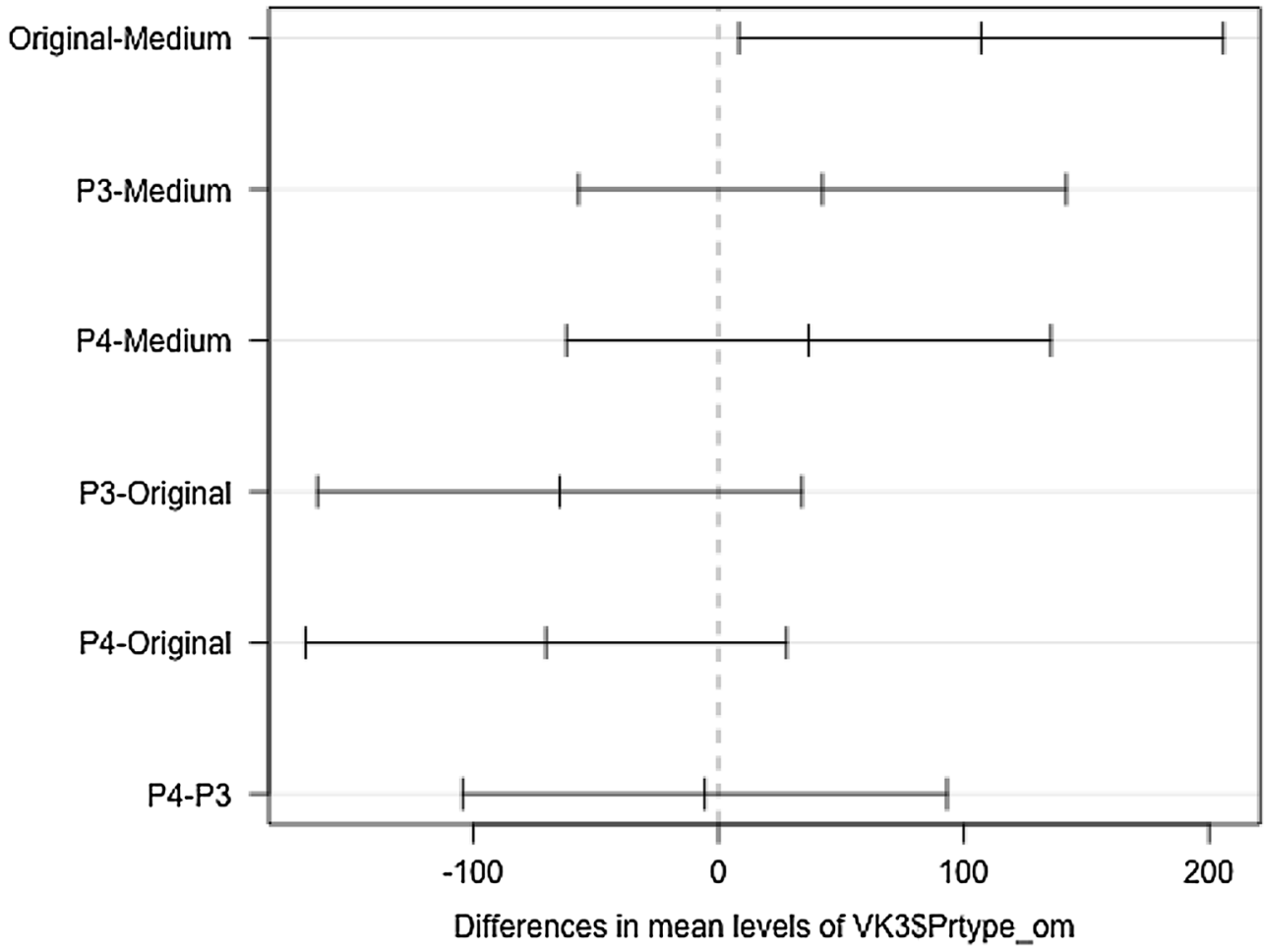

b

$95 \%$ family-wise confidence level

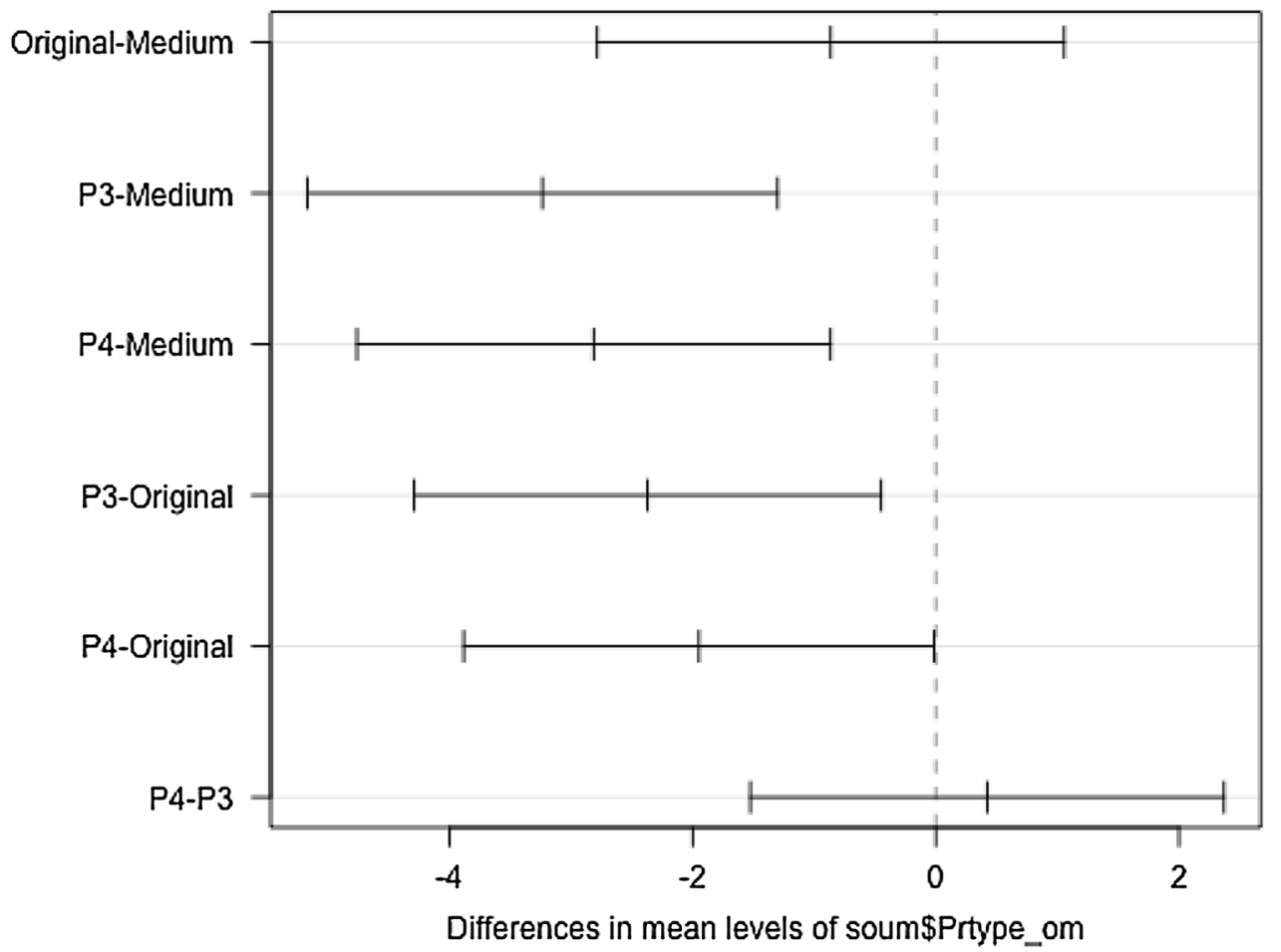

Fig. 9 Tukey multiple comparisons of means 95\% family-wise confident level a in VK3 and $\mathbf{b}$ in Soumousso 
Table 3 Gonotrophic status of female mosquitoes and number of males caught in trap versus house in both sites over the study period

\begin{tabular}{|c|c|c|c|c|c|c|}
\hline Village & Prototype or house & Unfed, \% (N) & Bloodfed, \% (N) & Gravid, \% (N) & Male, \% (N) & Total \\
\hline VK3 & Original & $39.27(7159)$ & $30.69(5594)$ & $6.9(1258)$ & $23.14(4219)$ & 18,230 \\
\hline VK3 & Medium & $37.58(3837)$ & 32.79 (3322) & $7.01(711)$ & $22.31(2260)$ & 10,130 \\
\hline VK3 & Prototype 3 & $27.42(3602)$ & $37.39(4911)$ & $5.89(774)$ & $29.30(3848)$ & 13,135 \\
\hline VK3 & Prototype 4 & $24.03(3148)$ & $46.27(6061)$ & $8.48(1111)$ & $21.22(2779)$ & 13,099 \\
\hline Soumousso & Original & $75.11(175)$ & $15.02(35)$ & $5.58(13)$ & $4.29(10)$ & 233 \\
\hline Soumousso & Medium & $77.51(224)$ & $12.46(36)$ & $5.88(17)$ & $4.15(12)$ & 289 \\
\hline Soumousso & Prototype 3 & $75.00(42)$ & $16.07(9)$ & $5.36(3)$ & $3.57(2)$ & 56 \\
\hline Soumousso & Prototype 4 & $47.62(40)$ & $30.95(26)$ & $9.52(8)$ & $11.90(10)$ & 84 \\
\hline VK3 & House & $23.05(4813)$ & $38.64(8067)$ & $14.57(3042)$ & $23.73(4955)$ & 20,877 \\
\hline Soumousso & House & $2.59(11)$ & $70.12(298)$ & $21.65(92)$ & $5.65(24)$ & 425 \\
\hline Total (VK3 + Sounousso) & Trap + house & $30.11(23,051)$ & $37.04(28,359)$ & 9.18 (7029) & $23.67(18,119)$ & 76,558 \\
\hline
\end{tabular}

NB: total in house $=$ number of mosquitoes collected in all houses over the study period

have found a reduced number of mosquitoes entering the house and the consequent protection of households against mosquito bites compared to houses without a screen $[19,29,30]$. In addition to house screening, other studies demonstrate that houses with fewer openings for mosquitoes to enter through can help reduce malaria transmission by lowering human exposure to infectious bites [31, 32]. Traps could have an additional, confounding effect when used with long-lasting insecticidal nets (LLINs) or Indoor Residual Spray (IRS), further decreasing the number of malaria vectors entering homes and biting occupants. Furthermore, trap efficiency in houses without suitable openings could be trapping mosquitoes that may escape any other malaria control measures in place (e.g. LLINs), and as a consequence, such traps could further protect the overall population in the village.

As such, the use of LFETs could be an effective and relatively simple method of reducing indoor mosquito vector densities generally in a local area, and consequently this could decrease malaria transmission and avert the harmful effects of other insects. This would be especially powerful in communities where all households commit to the LFET's proper use. This is in contrast to window

Table 4 Cost of manufacturing and length of metal used for the trap prototypes

\begin{tabular}{lll}
\hline Trap design & $\begin{array}{l}\text { Length of metal used } \\
(\mathbf{m})\end{array}$ & $\begin{array}{l}\text { Cost } \\
\text { of manufacturing } \\
\text { (US\$) }\end{array}$ \\
\hline Original & $\sim 15.81$ & $\sim 42$ \\
Medium & $\sim 12.51$ & $\sim 35$ \\
Prototype 3 & $\sim 13.23$ & $\sim 40$ \\
Prototype 4 & $\sim 13.58$ & $\sim 41$ \\
\hline
\end{tabular}

screening alone, as in this case mosquitoes are blocked from accessing a given house but are not trapped and so are free to continue to try to find a suitable place to feed, transmit pathogens, and reproduce. Traps do not discriminate by age or insecticide susceptibility, which is an issue with the insecticide-based malaria control tools. For instance, Vallée du Kou is an irrigated area where pesticides are extensively used in rice and cotton fields surrounding the village, and a significant proportion of mosquitoes exhibited high resistance level to pyrethroids $[19,21,33]$.

Malaria control is undermined by the growing proportion of outdoor feeding mosquitoes [9-11] due to the use of insecticide in LLINs and IRS. The LFET helps remove some outdoor fed mosquitoes looking for resting areas. In this study, An. gambiae was the main species collected in both sites. Female Anopheles mosquitoes regularly take blood meal every three days, and these are mostly in human dwellings [6-8]. During this study, the LFETs protected people from $43 \%$ of the blood seeking An. gambiae female mosquitoes.

The LFET is simple to produce locally, it contains no chemicals or attractants, it is easy to install, and it operates with no additional user work. The medium trap prototype is small enough to favour its use by owners while keeping its killing effect on mosquitoes. Considering the current cost, the LFET prototypes manufactured locally using other materials such as aluminium or recycled plastic, can reduce their mass-production for use at a village scale. Additionally, a long-term use of the LFET prototypes as malaria control tool requires low maintenance but cleaning. However, the frequency of cleaning would depend on the density of mosquitoes trapped over a given period. For instance, in endemic areas with high mosquito density, a monthly cleaning-period would be 
enough to deny attracting mosquito predators, which could damage the nettings. In low mosquito density area, the cleaning frequency would be performed according to the owner convenience. For the trap cleaning, the down sleeve could be untied and used by opening slowly to collect the dead mosquitoes while avoiding live mosquitoes' escapes.

During this LFET study, some parameters such as humidity, rainfall, temperature could not be assessed in the village, which could have enabled us to check the environment's effects on trap efficiency. These aspects are considered as limitations of this study and could be included in future studies.

\section{Conclusion}

When tested in both high and low mosquito density settings, the medium (P2) LFET design showed a promising level of performance in reducing mosquito numbers within dwellings. This suggests it may be used as a vector control tool to further suppress malaria mosquito populations. In addition, the trap protects residents from other harmful insects, such as vectors of arboviruses.

Although these new, smaller LFET prototypes have been developed and shown promise, further studies at a village scale will be needed to assess community acceptance of the traps, as well as their ability to control malaria vector populations.

\section{Supplementary Information}

The online version contains supplementary material available at https://doi. org/10.1186/s12936-020-03532-x.

Additional file 1: Fig. 10. (a) Number of mosquitoes collected per trap versus house in VK3 and (b) in Soumousso over the study period.

\section{Acknowledgements}

Authors are grateful to Tovi Lehmann, Adama Dao and Alpha Yaro, whose previous work inspired us to develop these new traps and with whom authors had fruitful discussion. Authors thank Guel Hyacinthe, Diabaté Noufou for their contribution to the fieldwork. Authors are also grateful to Ouedraogo K. Robert and Hien D. François de Sales, for their comments on the earlier version of the manuscript and to Traoré Nouhoun for drawing the pictures. Authors also thank Hanano Yamada and Kieran Callanan for English editing and the reviewers for their valuable comments and suggestions. Authors thank the villagers who accepted the traps to be tested in their houses. This work was funded by the Grand Challenges Canada (GCC, Grant ID: S6 0510-01-10) to DA.

\section{Authors' contributions}

RS carried out the field work, participated in the analysis of the data, and wrote the original manuscript. HM and EMB contributed to write and critically revised the paper. $A O$ carried out the social field work and revised the manuscript. PSS, KB, AMGB, LPT and RKD revised the manuscript. BBDS carried out the statistical analyses. DA designed the trap and the study and supervised the entire work. All authors have read and approved the final manuscript.

\section{Availability of data and materials}

All data generated and analysed during this study are available on Github: https://github.com/RogerSANOU/Lehmann-trap-dataset.git.

\section{Competing interests}

The authors declare that they have no competing interests.

\section{Author details}

${ }^{1}$ Institut de Recherche en Sciences de La Santé (IRSS)/Centre Muraz, Bobo-Dioulasso, Burkina Faso. ${ }^{2}$ Université Nazi BONI de Bobo-Dioulasso, PO 1091, Bobo-Dioulasso, Burkina Faso.

Received: 1 June 2020 Accepted: 7 December 2020

Published online: 01 January 2021

\section{References}

1. WHO. World Malaria Report 2017. Geneva World Health Organization [Internet]. 2017;196. Available from: http://apps.who.int/iris/bitst ream/10665/259492/1/9789241565523-eng.pdf?ua $=1$.

2. WHO. World malaria report [Internet]. Geneva World Health Organization, 2019. Available from: https://www.who.int/publications-detail/world -malaria-report-2019.

3. WHO Global Malaria Programme. Global plan for insecticide resistance management in malaria vectors. Geneva World Health Organization; 2012. p. 13.

4. Hemingway J, Shretta R, Wells TNC, Bell D, Djimdé A, Achee N, et al. Tools and strategies for malaria control and elimination: what do we need to achieve a grand convergence in malaria? PLoS Biol. 2016;14:e1002380.

5. Pombi M, Guelbeogo WM, Kreppel K, Calzetta M, Traoré A, Sanou A, et al. The sticky resting box, a new tool for studying resting behaviour of Afrotropical malaria vectors. Parasit Vectors. 2014;7:247.

6. Ekoko WE, Ambene PA, Bigoga J, Mandeng S, Piameu M, Nvondo N, et al. Patterns of anopheline feeding/resting behaviour and Plasmodium infections in North Cameroon, 2011-2014: implications for malaria control. Parasit Vectors. 2019;12:297.

7. Healy TP, Copland MJW. Activation of Anopheles gambiae mosquitoes by carbon dioxide and human breath. Med Vet Entomol. 1995;9:331-6.

8. Animut A, Balkew M, Lindtjørn B. Impact of housing condition on indoorbiting and indoor-resting Anopheles arabiensis density in a highland area, central Ethiopia. Malar J. 2013;12:393.

9. Okumu FO, Madumla EP, John AN, Lwetoijera DW, Sumaye RD. Attracting, trapping and killing disease-transmitting mosquitoes using odor-baited stations - the Ifakara Odor-Baited Stations. Parasit Vectors. 2010;3:12.

10. Pates $\mathrm{H}$, Curtis C. Mosquito behavior anc vector control. Annu Rev Entomol. 2005;50:53-70.

11. Russell TL, Govella NJ, Azizi S, Drakeley CJ, Kachur SP, Killeen GF. Increased proportions of outdoor feeding among residual malaria vector populations following increased use of insecticide-treated nets in rural Tanzania. Malar J. 2011;10:80.

12. Salako AS, Ahogni I, Kpanou C, Sovi A, Azondekon R, Sominahouin AA, et al. Baseline entomologic data on malaria transmission in prelude to an indoor residual spraying intervention in the regions of Alibori and Donga, Northern Benin. West Afr Malar J. 2018;17:392.

13. Charlwood JD, Pinto J, Ferrara PR, Sousa CA, Ferreira C, Gil V, et al. Raised houses reduce mosquito bites. Malar J. 2003;2:45.

14. United Nations Centre for Human Settlements. An urbanizing world: global report on human settlements. Nairobi: UNCHS; 1996.

15. Atieli H, Menya D, Githeko A, Scott T. House design modifications reduce indoor resting malaria vector densities in rice irrigation scheme area in western Kenya. Malar J. 2009;8:108.

16. Ogoma SB, Lweitoijera DW, Ngonyani H, Furer B, Russell TL, Mukabana WR, et al. Screening mosquito house entry points as a potential method for integrated control of endophagic filariasis, arbovirus and malaria vectors. PLoS Negl Trop Dis. 2010;4:e773.

17. von Seidlein L, Ikonomidis K, Mshamu S, Nkya TE, Mukaka M, Pell C, et al. Affordable house designs to improve health in rural Africa: a field study from northeastern Tanzania. Lancet Planet Health. 2017;1:e188-99.

18. Lindsay SW, Jawara M, Paine K, Pinder M, Walraven GEL, Emerson PM. Changes in house design reduce exposure to malaria mosquitoes. Trop Med Int Health. 2003:8:512-7.

19. Diabaté A, Bilgo E, Dabiré RK, Tripet F. Environmentally friendly tool to control mosquito populations without risk of insecticide resistance: the Lehmann's funnel entry trap. Malar J. 2013;12:196. 
20. Dabire KR, Diabate A, Namountougou M, Djogbenou L, Kengne P, Simard F, Bass C, Baldet T. Distribution of insensitive acetylcholinesterase (ace-1R) in Anopheles gambiae s.l. populations from Burkina Faso (West Africa). Trop Med Int Health. 2009; 14:396-403.

21. Namountougou M, Simard F, Baldet T, Diabate A, Martin T, Dabire RK. Multiple insecticide resistance in Anopheles gambiae s.l. populations from Burkina Faso. West Africa PLoS One. 2012;7:e48412.

22. Traoré A, Badolo A, Guelbeogo MW, Sanou A, Viana M, Nelli L, et al. Anopheline species composition and the 1014F-genotype in different ecological settings of Burkina Faso in relation to malaria transmission. Malar J. 2019;18:165.

23. Harbison JE, Mathenge EM, Misiani GO, Mukabana WR, Day JF. A simple method for sampling indoor-resting malaria mosquitoes Anopheles gambiae and Anopheles funestus (Diptera: Culicidae) in Africa. J Med Entomol. 2006:43:473-9.

24. Gillies MT, De Meillon B. The Anophelinae of Africa south of the Sahara (Ethiopian Zoogeographical Region). Publ South Afr Inst Med Res. 1968:54:343.

25. Barr RA, Smith TA, Boreham MM, White KE. Evaluation of some factors affecting the efficiency of light traps in collecting mosquitoes. J Econ Entomol. 1963;56:123-7.

26. Wilton DP, Fay RW. Air flow direction and velocity in light trap design. Entomol Exp Appl. 1972;15:377-86.

27. Curtis CF, Jana-Kara B, Maxwell CA. Insecticide treated nets: Impact on vector populations and relevance of initial intensity of transmission and pyrethroid resistance. J Vector Borne Dis. 2003;40:1-8.
28. Celli A. The new prophylaxis against malaria in Lazio. Lancet. 1900;156:1603-6.

29. Bradley J, Rehman AM, Schwabe C, Vargas D, Monti F, Ela C, et al. Reduced prevalence of malaria infection in children living in houses with window screening or closed eaves on Bioko Island, Equatorial Guinea. PLoS ONE. 2013;8:e80626.

30. Tusting LS, Ippolito MM, Willey BA, Kleinschmidt I, Dorsey G, Gosling RD, et al. The evidence for improving housing to reduce malaria: a systematic review and meta-analysis. Malar J. 2015;14:209.

31. Kirby MJ, West P, Green C, Jasseh M, Lindsay SW. Risk factors for houseentry by culicine mosquitoes in a rural town and satellite villages in the Gambia. Parasit Vectors. 2008;1:41.

32. Kirby MJ, Ameh D, Bottomley C, Green C, Jawara M, Milligan PJ, et al. Effect of two different house screening interventions on exposure to malaria vectors and on anaemia in children in The Gambia: a randomised controlled trial. Lancet. 2009;374:998-1009.

33. Diabate A, Baldet T, Chandre F. The role of agricultural use of insecticides in resistance to pyrethroids in Anopheles gambiae s.l. in Burkina Faso. Am J Trop Med Hyg. 2002;67:617-22.

\section{Publisher's Note}

Springer Nature remains neutral with regard to jurisdictional claims in published maps and institutional affiliations.
Ready to submit your research? Choose BMC and benefit from:

- fast, convenient online submission

- thorough peer review by experienced researchers in your field

- rapid publication on acceptance

- support for research data, including large and complex data types

- gold Open Access which fosters wider collaboration and increased citations

- maximum visibility for your research: over 100M website views per year

At BMC, research is always in progress.

Learn more biomedcentral.com/submissions 